\title{
Working together for global health goals: The United States Agency for International Development and faith-based organizations
}

\section{Clydette L Powell ${ }^{a}$}

${ }^{a}$ MD, MPH, Medical Officer, United States Agency for International Development; Associate Professor of Pediatrics (Neurology), The George Washington University School of Medicine and Health Sciences, Washington, DC

\begin{abstract}
For many years, and before the term "FBO" was used for faith-based organizations, the United States Agency for International Development (USAID) has supported the work of FBOs in global health and development. The Agency has long recognized the impact of FBOs within that development space, because these organizations are often well positioned to reach the hard-to-reach and to go the last mile because of their strong ties to the community. Moreover, FBOs deliver a substantial percentage of the health services in some developing countries. Faith partners, whether Catholic, Protestant, Buddhist, Hindu, Muslim, or other, have an important role to play as implementers in global health and to support global efforts towards achieving the Millennium Development Goals (MDGs) in health. In addition, partnerships at national and international levels are key to the success of US Presidential Initiatives in the developing world, such as President's Emergency Plan for AIDS Relief (PEPFAR) and President's Malaria Initiative (PMI). FBOs also have an important voice in policy and strategy formulation. Among other international donors, USAID support has been of great importance to the work of FBOs, thereby helping host nations to achieve goals in ending preventable child and maternal deaths, improving communicable disease control and prevention, and by supporting the construction and renovation of hospitals and health facilities where service delivery is most needed. The development literature is replete with examples of the work of FBOs made possible through access to resources. This paper focuses on some of the work supported by USAID in global health initiatives in order to reach complementary goals and achieve significant public health advances. Given the vastness of the topic, not all the global health initiatives involving FBOs supported by USAID are included here; the reader is encouraged to access the USAID website and USAID implementing partners for further information.
\end{abstract}

\section{Introduction}

Collaboration with faith-based organizations (FBO) has been integral to the work of the United States Agency for International Development
(USAID) for more than fifty years. Within the health sector, this partnership spans both time and geography to serve the health needs of vulnerable populations and communities in the developing world. Faith leaders and faith organizations are

Nov 2014. Christian Journal for Global Health, 1(2):63-70. 
closely linked with the communities they serve culturally, spiritually, and physically. They often represent and are composed of trusted individuals whose lives, beliefs, and cultural values are aligned with their beneficiaries. They know intimately the networks - both formal and informal - as well as the opinion leaders, the history, the behaviors, and the practices which have strengthened or weakened the communities they seek to serve. They are often rich in experience and knowledge, but may be lacking in sufficient resources to do their work. They are mobile and adept but may not be able to wield the necessary influence for change at the upper echelons of a ministry of health, which can be far removed from the details of community life and common people's struggles. Therefore, the partnership of a large donor with FBOs as implementers can be a significant advantage to mutual goals and objectives. The development literature is replete with examples of the work of FBOs made possible through access to resources. This paper focuses on some of the work supported by USAID in global health initiatives in order to reach complementary goals and achieve significant public health advances. Given the vastness of the topic, not all the global health initiatives involving FBOs supported by USAID are included here; the reader is encouraged to access the USAID website and USAID implementing partners for further information. ${ }^{1}$

\section{USAID's Overall Approach to FBOs}

In the selection of its partners, USAID neither discriminates for or against organizations based on their faith-based character or affiliation. ${ }^{2}$ However, USAID regularly partners and works with FBOs and religious leaders, and those partnerships are, in fact, key to the Agency's work. ${ }^{3}$ Many such organizations are among USAID's largest implementing partners. ${ }^{4}$

In 2002, to coordinate outreach to, and engagement with, the broad range of faith and community organizations and to ensure a level playing field for these organizations, the Center for Faith Based and Community Initiatives (CFBCI) at USAID was established by a Presidential Executive Order. ${ }^{5,6}$ As with the Bureau for Global Health (BGH), the CFBCI supports engagement with the faith-based community through published evidence and case examples, and mutual learning among USAID's bureaus and field missions. Under USAID Forward, an Agencywide initiative for better management and business practices, the CFBCI opened up new ways to partner with faith-based organizations on the ground, including innovative business models headed by business leaders who are faithaffiliated. $^{7}$

Even before the establishment of CFBCI, Christian Connections for International Health $(\mathrm{CCIH})$ had engaged in development dialog with USAID. Over the years, CCIH has represented its member organizations by raising the visibility and voice of FBOs working in global health, thereby reflecting the unique quality that faith can bring to addressing development challenges. ${ }^{8}$.

\section{USAID's global health engagement with FBOs}

USAID's engagement in global health with FBOs takes many forms. The Agency aims to make progress towards the Millennium Development Goals (MDG) 4 and 5, to save children's lives and to improve the health and welfare of mothers and families. It works to mitigate the impact of malaria and of HIV/AIDS on families, orphans, and vulnerable children. It helps to support the reconstruction and rehabilitation of schools and hospitals abroad, thereby improving access and quality of health services to remote or marginalized populations. USAID also has less structured interaction, for example with US churches, as well as the music/arts community. ${ }^{9,10}$

\section{Child survival}

Since 1985, the Child Survival and Health Grants Program (CSHGP) has evolved to address the major strategic needs of USAID, national 
governments, and vulnerable communities. Of the 457 projects supported through the CSHGP since 1985 , approximately $30 \%$ have been awarded to FBOs and have strengthened their technical capacity and leadership role in global health. ${ }^{11}$

In June 2012, USAID hosted the Child Survival Call to Action with the governments of Ethiopia, India, and the US, in conjunction with UNICEF. Leading up to that summit, the White House Office of Faith Based and Neighborhood Partnerships, along with USAID's BGH and CFBCI, organized a conference call with over 150 faith leaders on USAID's efforts on child survival and urged their support for this work. In October 2013, USAID co-sponsored an all-day meeting with over 500 FBOs and leaders to launch the lifesaving pledge, "Ten Promises to Our Children". ${ }^{12}$ More than 290 faith leaders and 90 FBOs from over 50 countries signed the pledge - a pledge that will reach more than 260 million people.

\section{Women's health}

USAID's Office of Population and Reproductive Health (PRH) within the Bureau for Global Health has a long history of support for and collaboration with Catholic, Protestant, and Muslim FBOs to expand family planning (FP) options to underserved populations. One such example is USAID's support to Georgetown University's Institute for Reproductive Health (IRH) through the Fertility Awareness-based Methods (FAM) Project. ${ }^{13,}{ }^{14}$ Fertility awarenessbased methods are favored by some FBOs promoting natural FP (NFP). ${ }^{15}$ In the Democratic Republic of Congo,${ }^{16}$ Honduras, ${ }^{17}$ and India, ${ }^{18}$ collaboration has led to NFP acceptance and promotion by religious leaders. ${ }^{19}$ In 2011 USAID began collaborating with the Organization of Islamic Conferences (OIC) to promote advocacy, training, and community services in maternal and child health $(\mathrm{MCH})$, as well as to revise national $\mathrm{MCH}$ strategies, e.g., in Bangladesh and Mali. ${ }^{20,21}$

\section{HIV/AIDS}

Created under the U.S. President's Emergency Plan for AIDS Relief (PEPFAR), and launched in 2005, the New Partners Initiative (NPI) was PEPFAR's signature effort to help new and diverse partners build their capacity to fight HIV/AIDS at the local level in PEPFAR focus countries. $^{22}$ Through NPI, USAID supported 14 FBOs and more than 60 sub-grantees to provide services to orphans and vulnerable children (OVCs) in eight countries. ${ }^{23}$

In Cambodia, USAID funding to the Khmer HIV/AIDS NGO Alliance facilitates some FBOs to implement the HIV Home and Community Based Care as part of its response to HIV/AIDS in Cambodia. Within this Alliance, The Salvation Centre Cambodia, ${ }^{24}$ Buddhism for Development, ${ }^{25}$ and Buddhism for Social Development Action $^{26}$ work with teams of Buddhist monks, nun trainers, and field volunteers to implement HIV/AIDS prevention and care activities, improve living conditions of people living with HIV/AIDS and OVCs, and reduce HIV transmission, deaths, and discrimination.

In Zambia, the STEPS OVC Project provides standardized and sustainable HIV prevention, care, and support services, through seven FBOs. ${ }^{27,} 28$ In Namibia, the Church Alliance for Orphans (CAFO) mobilizes community-based responses to the needs of OVC as part of the PEPFAR Partnership Framework. ${ }^{29}$

\section{Malaria control and prevention}

Partnerships at national and international levels are key to the success of the President's Malaria Initiative (PMI). PMI's investments are strategically targeted to support each focus country's malaria control strategy and plan and coordinate with many international, national, and local partners, including FBOs working in underserved, rural areas where malaria is a major public health problem and where formal health services may be limited. $^{30}$ By the end of 2013, PMI had supported 
malaria activities through more than 200 local and international nonprofit organizations in all PMI focus countries, approximately one-third of which are FBOs. Some country examples include social and behavioral changes in Mozambique, ${ }^{31}$ rapid diagnostic testing in Madagascar, ${ }^{32}$ extensive insecticide-treated nets (ITN) distribution campaigns in Ghana, ${ }^{33}$ collaboration with Koranic schoolmasters in Senegal, ${ }^{34}$ and a National Voucher Scheme in Tanzania. ${ }^{35}$

\section{Pharmaceutical Systems}

Formed in 1981, the Ecumenical Pharmaceutical Network (EPN) is a faith-based organization in Africa that supports its constituency with equitable and compassionate quality pharmaceutical services. EPN has a constituency of more than 80 Anglophone and Francophone members from over 30 countries. USAID's technical support to EPN has strengthened the procurement function of its member Drug Supply Organizations, promoted good governance and operations efficiency, and helped to contain antimicrobial resistance. In addition, EPN is a resource partner on the USAIDfunded Systems for Improved Access to Pharmaceuticals and Services program and serves as a liaison to USAID field missions in developing countries. $^{36}$

\section{Health Facility Construction and Ren- ovation}

USAID's American Schools and Hospitals Abroad (ASHA) program provides assistance to secondary schools, universities, libraries, and medical centers outside the US that serve as study and demonstration centers for American ideas and practices. ASHA awards support construction, renovation, and the procurement of scientific, medical, and educational equipment. Since ASHA's inception in 1947, USAID has assisted more than 250 institutions in over 70 countries and currently manages a worldwide portfolio of over 100 awards. Many of the partners ASHA works with are faith-based, since missionaries established numerous hospitals and schools in the nascent years of American foreign aid. Prime examples include the Christian Medical College and Hospital, in Vellore, India and CURE International's network in Ethiopia, Afghanistan, Zambia, Uganda and the Philippines. ${ }^{37,38}$

\section{Conclusion}

For many years, and before the term "FBO" was defined, USAID has supported the work of FBOs in global health and development. The Agency has long recognized the impact that FBOs have within that development space, because these organizations are often well positioned to reach the hard-to-reach and to go the last mile because of their strong ties to the community. Moreover, FBOs deliver a substantial percentage of the health services in some developing countries. Faith partners, whether Catholic, Protestant, Buddhist, Hindu, Muslim, or other, have an important role to play as implementers in global health and to support global efforts towards achieving MDGs in health. In addition, partnerships at national and international levels are key to the success of US Presidential Initiatives in the developing world, such as PEPFAR and PMI. FBOs also have an important voice in policy and strategy formulation. Among other international donors, USAID support has been of great importance to the work of FBOs, thereby helping host nations to achieve goals in ending preventable child and maternal deaths, improving communicable diseases control and prevention, and supporting the construction and renovation of hospitals and health facilities where service delivery is most needed.

\section{References and Endnotes}

1. http://www.usaid.gov/what-we-do/global-health

2. USAID also does not track funding in this way. The laws governing its work do not permit USAID to 
track data on whether an organization is "faith-based", as such organizations are exempt from reporting that fact during the registration process.

3. http://www.usaid.gov/work-usaid/partnershipopportunities/faith-based-communityorganizations/faith-based-organizations

4. Catholic Relief Services (CRS) and World Vision are among USAID's top 20 implementing partners, receiving hundreds of millions of dollars per annum. In addition, over a third of the American Schools and Hospital Abroad grantees for the past few years have been faith-based or faith-inspired organizations.

5. Current priorities of the CFBCI include key US Government (USG) and USAID initiatives, such as child survival and maternal health, counter-trafficking in persons, Food Aid Reform, and the Interagency Strategy for Global Faith Leader Engagement. In addition, CFBCI seeks to leverage faith and community ties to secure increased support for USAID from Congress and to support the Agency Administrator's actions on key initiatives and priorities to advance the MDGs.

6. As an independent office within the USAID Administrator's Office, CFBCI is a part of the network of 13 faith-based centers within federal departments and agencies coordinated by the White House Office of Faith-based and Neighborhood Partnerships.

7. For example, in 2012, USAID Rwanda signed grants with three civil society organizations (Caritas Rwanda, African Evangelistic Enterprise Rwanda, and FXB Rwanda), two of which are faith based. At USAID's Local Capacity Development Summit in 2012, Catholic Relief Services (CRS) shared how they work to develop capacity of local organizations. Another example is a business franchise model, represented by an integrated platform in the Democratic Republic of Congo, and designed to save lives through health care, nutrition, and clean water. With an $\$ 800,000$ grant to support development of the model and proof of concept, Asili is backed by a consortium of non-profits and businesses led by the American Refugee Committee. It will be open for business in 2014. Many of those involved are faith-affiliated business leaders.
8. In a forward thinking way, CCIH took the step of entering into the sensitive area of family planning around 2006. It received grants from the USAID's Flex Fund and worked with USAID to obtain Flex funding for other member organizations. Over the years, USAID assistant administrators and staff have been invited to speak at $\mathrm{CCIH}$ annual conferences, and former USAID staff have served on CCIH's Board. The Executive Director (ED) of CCIH had been a USAID Foreign Service Office for 25 years before his service at $\mathrm{CCIH}$; he served as CCIH's first ED for 14 years.

9. USAID staff has been working with Saddleback Church in southern California in two areas: (1) Saddleback's development and deployment of over 6,500 community health volunteers (PEACE Servants) in Rwanda; and (2) the Saddleback Orphan Care Initiative. The Saddleback Orphan Initiative provided ongoing guidance and support to the development of the U.S. Government Plan of Action on Children in Adversity which was launched in December 2012.

10. Grammy Award winning band Jars of Clay, which also founded the NGO, Blood:Water Mission, to address needs in Africa around water and AIDS, endorsed the USG's Global Water Strategy and provided a video in support of its launch from their tour in Europe. In March of 2014, Jars members met with staff at USAID's Washington offices to discuss their efforts and hear of USAID's current work on water and AIDS. They promoted the visit to their fans via social media. Jars' Facebook following is over 500,000 individuals, and their Twitter following is close to 100,000 .

11. The CSHGP's current active portfolio leverages the leadership of four FBOs in six countries through five innovative projects by Catholic Relief Services, World Renew (formerly Christian Reformed World Relief Committee), World Relief, and World Vision.

12. These focused on actions that parents and communities could do, such as making sure young children were vaccinated, that they slept under bed nets, that they received timely health services, and that children were taught to wash their hands.

13. http://irh.org/resource-library/faith-basedorganizations-as-partners-in-family-planning-working- 
together-to-improve-family-well-being/ from the Institute for Reproductive Health, Georgetown University, August 2011

\section{4. http://irh.org/projects/fam_project/}

15. Standard Days Method, TwoDayMethod, and Lactational Amenorrhea Method. Other FAM includes Billings Method and the Sympto-thermal method.

16. IRH's collaboration with Mamans AN'SAR, a group of Muslim women, led to endorsement of NFP by Muslim religious leaders. Similar collaborative work was done by Conduite de la Fecondite, a Catholic NGO in DRC.

17. In Honduras, a Catholic-based organization now serves as a national resource on NFP to the Ministry of Health.

18. In India, World Vision integrates NFP into their child survival and birth spacing projects. The Catholic Bishops Conference of India oversees the country's Catholic health facilities, which account for nearly onequarter of health facilities in India, serving rural, hardto-reach areas. Collaboration with IRH led to advocacy, training, and development of educational materials on NFP.

19. In similar fashion, IRH work in Kenya, Rwanda, Mali, and Timor-Leste has led to sensitization of Catholic, Protestant, and Muslim leaders with regard to NFP.

20. Collaboration between the OIC, USAID, and the Ministry of Health and Family Welfare (MOHFW) in Bangladesh led to revision of the National Maternal Health Strategy. UNICEF, WHO and USAID's MCHIP program provided the necessary financial, technical and coordination support that facilitated a national participatory and consultative process that involved more than 100 professionals from government, UN, NGOs, FBOs, and other stakeholders.

21. In Mali, a joint USAID-OIC communication initiative resulted in religious leaders' support for postpartum family planning (PPFP) and healthy timing and spacing of pregnancy. Additionally, USAID's Health Policy Project strengthened the capacity and support of religious leaders at national and district levels for PPFP. Nearly 200 Islamic leaders were also trained on advocacy tools regarding malaria, pregnancy, and HIV/AIDS. With the support of religious leaders, women's groups and messages through local radio stations mobilized women on reproductive health issues for family well-being.

22. The NPI selected NGOs and FBOs which were capable of reaching people who needed HIV/AIDS services but who lacked the experience in working with the USG.

23. The partners served more than 200,000 OVC between 2007 and 2012 and received technical and organizational capacity-building not only to improve services, but also to provide services over the long term. Currently USAID serves over 3 million children and their families through thousands of local and international faith-based partners throughout the world.

24. SCC has helped more than 400 poor families with its services, along with 700 PLHIV and more than $2,000 \mathrm{OVC}$

25. Buddhism for Development (BFD) has achieved significant milestones since 1992 in collaboration with their field-based monks and nuns.

26. Since 2005, Buddhism for Social Development Action (BSDA) provides integrated HIV prevention and $\mathrm{HCBC}$, education and vocational training for OVC; and community and democracy development. BSDA is currently providing HIV/AIDS care, support, and counseling to over 600 PLHIV and more than 600 OVC.

27. STEPS is a three-year USAID-funded grant. By 2012, STEPS OVC scaled up quality, comprehensive care, and support to 320,000 OVC.

28. These included Catholic Relief Services, Expanded Church Response, and Salvation Army. By 2012, STEPS OVC scaled up quality, comprehensive care and support to 320,000 OVC. World Vision International was the lead partner.

29. CAFO targets OVC and their caregivers in 12 regions in Namibia. An indigenous civil society 
organization of over 500 member congregations, and formed as an inter-denominational umbrella organization, CAFO promotes local action by church congregations and communities to mitigate the impact of HIV on children.

30. PMI support is improving community-level access to critical malaria prevention and treatment services while also building local capacity and ensuring program sustainability.

31. Starting in 2007, PMI has provided support to improve the organizational and management capacity of an interfaith network in Mozambique, the Programa Inter-religioso Contra a Malaria (PIRCOM). PMI's technical assistance to PIRCOM for a social behavior change and communication program ensured that in four provinces $95 \%$ of the population received key messages on malaria prevention, diagnosis, and treatment. During FY 2012, PIRCOM trained more than 6,000 religious leaders on key malaria messages. These religious leaders in turn have reached approximately 100,000 people in 35 districts

32. PMI supported Madagascar's NGOs and FBOs in their implementation of the National Strategic Plan for Malaria Control. Moreover, these groups introduced and expanded malaria case management, including rapid diagnostic testing and supply chain management, in health facilities operated by local NGOs and FBOs in all 22 of the country's regions. A formal agreement was established in which organizations agreed to provide rapid diagnostic tests (RDTs) free-of-charge to patients and to report cases in exchange for a supply of RDTs procured by PMI. This support occurred after Madagascar's coup d'etat in 2009.

33. In 2010, under the leadership of Ghana's National Malaria Control Program, PMI partnered with Malaria No More, Comic Relief, UNICEF, WHO, Nets for Life, the Anglican Diocesan Development and Relief Organization, and others to launch the first in a series of long-lasting insecticide-treated nets (ITN) distribution campaigns designed to reach every region in Ghana. PMI's contribution included providing more than 950,000 long-lasting ITNs, logistics support, training, technical assistance, and post-campaign evaluation. Through diligent door-to door work in 2010, some 10,000 volunteers distributed and hung more than
560,000 long-lasting ITNs to cover children under five and pregnant women. As a result, household ownership of at least one ITN increased from $28 \%$ in 2008 to $82 \%$ in 2010, ITN use among children under five years old increased from $11 \%$ to $52 \%$, and ITN use among pregnant women increased from 7 to $39 \%$.

34. PMI works with Koranic schoolmasters to extend community-based treatment for malaria to vulnerable populations.

35. PMI supports the distribution of ITNs through the Tanzania National Voucher Scheme in partnership with the FBO Mennonite Economic Development Associates. Sources: 6th, 7th, and 8th PMI Annual Reports, USAID

36. EPN's role also includes coordination and networking, development and provision of technical assistance on pharmaceutical policy and services, human resources capacity development, and consumer/patient education related to pharmaceutical management and medicines use.

37. Founded in 1900 by an American missionary, CMC Vellore has served more than 23 million patients, and enrolls nearly 2,000 students annually. CMC Vellore is one of best hospitals and one of the top ranked medical colleges in India. ASHA funding to Vellore helped to procure equipment to improve the hospital's efficiency and quality of care, including an electronic medical record system and a new library for the college of nursing. Over the last decade ASHA has provided CMC Vellore with more than \$2 million dollars.

38. CURE International is a network of charitable hospitals and surgical programs which deliver medical care and Christian values to children and families. Since 1998, CURE has helped more than 2 million patients, performed over 167,000 surgeries, and trained over 7,200 medical professionals in more than 30 countries. Over the last five years, ASHA has worked with CURE to procure medical equipment, build and renovate hospitals in Ethiopia, Afghanistan, Zambia, Uganda and the Philippines. Most recently, ASHA provided CURE with $\$ 379,000$ to procure commodities to support surgical services and training at Tebow CURE Hospital in Davao, Philippines. 
Disclaimer: The author's views expressed in this article do not necessarily reflect the views of USAID or the US Government.

Peer Reviewed

Competing Interests: None declared.

Acknowledgments: Staff at USAID, as well as $\mathrm{CCIH}$, contributed information and case examples. Special thanks to USAID's Victoria Graham for encouragement to write this article, and for her long-standing leadership and support to FBOs. Jeffrey Spieler generously served as a reviewer prior to formal peer review.

Correspondence: Clydette Powell. USAID. cpowell@usaid.gov

Cite this article as: Powell CL. Working together for global health goals: The United States Agency for International Development and faith-based organizations. Christian Journal for Global Health (Nov2014), 1(2):6370. http://dx.doi.org/10.15566/cjgh.v1i2.36

(C) Powell CL. This is an open-access article distributed under the terms of the Creative Commons Attribution License, which permits unrestricted use, distribution, and reproduction in any medium, provided the original author and source are properly cited. To view a copy of the license, visit http://creativecommons.org/licenses/by/3.0/

www.cjgh.org 